\title{
Depression in People With Dementia and Caregiver Outcomes: Results From the European Right Time Place Care Study
}

Citation for published version (APA):

Parrotta, I., De Mauleon, A., Abdeljalil, A. B., Barreto, P. D., Lethin, C., Veerbek, H., Stephan, A., Saks, K., Zabalegui, A., \& Martin, M. E. S. (2020). Depression in People With Dementia and Caregiver Outcomes: Results From the European Right Time Place Care Study. Journal of the American Medical Directors Association, 21(6), 872-878.e1. https://doi.org/10.1016/j.jamda.2020.02.023

Document status and date:

Published: 01/06/2020

DOI:

10.1016/j.jamda.2020.02.023

Document Version:

Publisher's PDF, also known as Version of record

Document license:

Taverne

Please check the document version of this publication:

- A submitted manuscript is the version of the article upon submission and before peer-review. There can be important differences between the submitted version and the official published version of record.

People interested in the research are advised to contact the author for the final version of the publication, or visit the DOI to the publisher's website.

- The final author version and the galley proof are versions of the publication after peer review.

- The final published version features the final layout of the paper including the volume, issue and page numbers.

Link to publication

\footnotetext{
General rights rights.

- You may freely distribute the URL identifying the publication in the public portal. please follow below link for the End User Agreement:

www.umlib.nl/taverne-license

Take down policy

If you believe that this document breaches copyright please contact us at:

repository@maastrichtuniversity.nl

providing details and we will investigate your claim.
}

Copyright and moral rights for the publications made accessible in the public portal are retained by the authors and/or other copyright owners and it is a condition of accessing publications that users recognise and abide by the legal requirements associated with these

- Users may download and print one copy of any publication from the public portal for the purpose of private study or research.

- You may not further distribute the material or use it for any profit-making activity or commercial gain

If the publication is distributed under the terms of Article $25 \mathrm{fa}$ of the Dutch Copyright Act, indicated by the "Taverne" license above, 
Original Study

\title{
Depression in People With Dementia and Caregiver Outcomes: Results From the European Right Time Place Care Study
}

\author{
Ilaria Parrotta $\mathrm{MD}^{\mathrm{a}, \mathrm{b}, *}$, Adelaide De Mauleon $\mathrm{MD}^{\mathrm{b}}$, Anne Bahia Abdeljalil MD ${ }^{\mathrm{b}}$, \\ Philipe De Souto Barreto $\mathrm{MD}^{\mathrm{b}}$, Connie Lethin $\mathrm{PhD}^{\mathrm{c}}$, Hilde Veerbek $\mathrm{PhD}^{\mathrm{d}}$, \\ Astrid Stephan $\mathrm{MD}^{\mathrm{e}}$, Kay Saks MD, $\mathrm{PhD}^{\mathrm{f}}$, Adelaida Zabalegui $\mathrm{RN}, \mathrm{PhD}^{\mathrm{g}}$, \\ Maria Eugenia Soto Martin MD, $\mathrm{PhD}^{\mathrm{b}}$
}

\author{
a Department of Geriatric and Internal Medicine, La Sapienza University of Rome, Rome, Italy \\ ${ }^{\mathrm{b}}$ Centre Hospitalier Universitaire de Toulouse, Toulouse, France \\ ${ }^{c}$ Faculty of Medicine, Department of Health Science, Lund University, Lund, Sweden \\ ${ }^{\mathrm{d}}$ Department of Health Service Research, Maastricht University, Maastricht, Netherlands \\ ${ }^{\mathrm{e}}$ Wissenschaftliche Mitarbeiterin Martin-Luther-Universität Halle-Wittenberg Medizinische Fakultät Institut für Gesundheits- und Pflegewissenschaft, \\ Wittenberg, Germany \\ ${ }^{\mathrm{f}}$ University of Tartu, Tartu, Estonia \\ ${ }^{\mathrm{g}}$ Hospital Clínic de Barcelona, Barcelona, Spain
}

Keywords:

Depression

dementia

caregiver

burden

elderly

\begin{abstract}
A B S T R A C T
Objective: To investigate the cross-sectional associations between depression in people with dementia and both caregiver burden and quality of life in 8 European countries, and to test these associations compared with the presence of other neuropsychiatric symptoms.

Design: Cross-sectional study.

Setting and Participants: In total, 1223 dyads comprised of informal caregivers and people with dementia living in a community-dwelling setting, recruited from the Right Time Place Care study, a cohort survey from 8 European countries.

Measures: To test the associations between depression (according to the Cornell Scale for Depression in Dementia) and informal caregiver burden (defined by the Zarit scale and hours of supervision in terms of Resource Utilization in Dementia), distress (defined by the Neuropsychiatric Inventory Questionnaire distress score), and quality of life (according to the visual analogue scale and 12-item General Health Questionnaire).

Results: Linear regressions showed an association between depression and main outcomes (Zarit scale: $\beta$ 3.7; $P=.001$; hours of supervision: $\beta 1.7 ; P=.004$; Neuropsychiatric Inventory Questionnaire distress score: $\beta 1.2 ; P=.002)$. A similar association was found concerning psychological and overall well-being (12-item General Health Questionnaire: $\beta$ 1.8; $P<.001$; Euroqol Visual Analogue Scale: $\beta-4.1 ; P=.003$ ). Both associations remained significant despite the presence of other NPS and after adjusting for confounders.

Conclusions and Implications: Further studies are needed to assess whether providing tailored strategies for optimizing diagnosis and managing of depression in people with dementia might improve caregiver quality of life and reduce their burden in the community-dwelling setting.
\end{abstract}

(c) 2020 AMDA - The Society for Post-Acute and Long-Term Care Medicine.
The Right Time Place Care study was funded by a grant from the European Commission within 7th Framework Program (Project 242153).

The authors declare no conflicts of interest.

* Address correspondence to Ilaria Parrotta, MD, Department of Geriatrics and Internal Medicine, La Sapienza University of Rome, Rome, Italy.

E-mail address: Ilaria.parrotta@gmail.com (I. Parrotta).
Around the world, there are currently 50 million people living with dementia, and this number could rise up to 152 million by $2050 .{ }^{1}$ It is well-known that the pathologic mechanisms underpinning this disease not only lead to cognitive dysfunctions but also to behavioral and psychological disorders or neuropsychiatric symptoms (NPSs). Almost $90 \%$ of people affected by dementia will present with NPS during the course of the disease., ${ }^{2,3}$ In the community-dwelling setting, NPSs in people with dementia are often associated with caregiver's adverse 
outcomes such as depression, reduced quality of life, and increased burden and distress. ${ }^{4-6}$ On the other hand, the increase of caregiver burden could result in a reduction of care for the patient with dementia leading to an increased rate of institutionalization and healthcare costs. ${ }^{4,7,8}$ Previous research investigating the impact of NPSs on caregiver burden and well-being mostly used an overall view of these symptoms; $;^{9-11}$ however, to our knowledge, none specifically focused on depression. Published data on the prevalence of depression in patients with dementia are conflicting, with a variation of the estimated prevalence from $4 \%$ to $40 \%{ }^{12,13}$ Depression may occur in different phases of dementia or could represent a risk factor of its onset. ${ }^{14,15}$ The heterogeneity of the onset of depression, in the context of dementia, makes it difficult to clarify the possible links between these diseases. The presence of depression in people with dementia hastens cognitive decline, increases the risk of disability and mortality in patients, and increases the informal caregiver burden., 95,16 Currently, the effect of depression on burden, distress, and quality of "life of the informal caregiver" compared with other NPSs is not known.

The main goal of this study was to describe the characteristics of people with dementia affected by depression living in the communitydwelling setting in 8 European countries and to investigate the associations between depression and caregiver burden and quality of life using data from the Right Time Place Care (RTPC) study. Moreover, a secondary goal of this study was to evaluate the associations between depression and caregiver burden and quality of life compared with the presence of other NPSs.

\section{Methods}

\section{Study Design and Study Population}

The RTPC study is a prospective cohort survey conducted in 8 European countries (Finland, Sweden, Germany, Estonia, England, Spain, France, and the Netherlands). ${ }^{17}$ The general goal of the RTPC study was to evaluate the transition of people with dementia from home care to institutional long-term care facilities (LTCFs), assessing quality of life and care in people with dementia and their informal caregivers in LTCFs and the community-dwelling setting. Participants were recruited if (1) they were recently admitted into a LTCF; and (2) they lived at home, had an identified informal caregiver, received professional care, and were at risk of institutionalization, defined as risk of admission within the next 6 months.

After baseline assessments, 1 follow-up visit was performed after 3 months from the period of inclusion, between November 2010 and December 2011. Main criteria of inclusion were patients over 65 years old, a primary diagnosis of dementia, and a Standardized Mini-Mental State Examination (SMMSE) ${ }^{18}$ score under 24, together with the presence of an informal caregiver for those living in the communitydwelling setting. More details of RTPC study methods are available elsewhere. $^{17}$

For the purpose of this study, only the data collected at baseline of the dyads living in the community-dwelling setting were included in the analysis $(\mathrm{n}=1223)$.

\section{Procedures}

Eligible people with dementia and their informal caregiver were recruited at home by professionals in health or social care or medical/ nursing/social care professionals with clinical experience and at least a bachelor's degree. All the participants gave their informed consent, and if the people with dementia were not able to provide a consent, a legal authorization was obtained, according to country-specific regulations. A manual that included the standardized operating procedures was furnished to all the participating countries by the leading center (Maastricht University, the Netherlands); all delivered data were centrally managed by the RTPC coordinating center (Witten University, Germany). Ethical approval was granted by the German Society for Nursing Science and by ethical committees of all the participating countries in August 2011; the study was carried out in accordance with the Helsinki Declaration (https://www.wma.net/en/ 30publications/10policies/b3/index.html). Further information is available elsewhere. $^{17}$

\section{Main Outcomes}

For the current study, burden, distress, and quality of life of informal caregiver were our main outcomes. The burden of informal caregiver was assessed by the Zarit scale and with the Neuropsychiatric Inventory Questionnaire (NPI-Q) distress score. The Zarit scale ranged from 0 to 88 with a higher score indicating a higher burden. ${ }^{19}$ The distress of the informal caregiver was based on the NPI-Q distress score, which ranged from 0 to 5 , with a higher score defining a higher distress. ${ }^{19}$

In addition, the time invested by the informal caregiver was assessed in terms of hours of supervision per day. The hours of supervision, assessed using the Resource Utilization in Dementia questionnaire, ${ }^{20}$ indicate the time spent by the informal caregiver to avoid dangerous events and to manage NPSs. ${ }^{20,21}$ Informal caregiver's quality of life was assessed using 2 self-reported rating scales of wellbeing. The EuroQol Visual Analogue Scale (EQ-VAS) is the second part of health-related quality of the live questionnaire (EuroQol FiveDimensional). ${ }^{22}$ It ranges from 0 to 100 , a higher score indicating a higher quality of life. The psychometric properties of the EQ-VAS have been tested in patients and caregivers. ${ }^{23,24}$ The General Health Questionnaire (GHQ-12) is a self-reported scale of psychological wellbeing ranging from 0 to 36 with an inverse proportional ratio to quality of life. ${ }^{25}$ All main outcome variables were evaluated as continuous variables.

\section{Assessment of Depression}

Presence of depression was evaluated using the Cornell Scale for Depression in Dementia (CSDD). This scale consists of 19 items ranging from 0 to 36 , with a higher score defining severe depression. ${ }^{21}$ CSDD was assessed using the informal caregiver reports. People with dementia with depression were defined according to a CSDD score of $\geq 12$, already defined and validated in the literature. ${ }^{26,27}$

\section{Confounders}

Confounders included were level of disability based on activities of daily living according to the Katz questionnaire, ${ }^{22}$ comorbidity using the Charlson comorbidity index, ${ }^{23}$ cognitive status defined by the SMMSE, ${ }^{24}$ and demographic characteristics (sex and age of people with dementia and caregiver). The SMMSE is a faster test with less interobserver variability than the Mini-Mental State Examination. ${ }^{18}$ Other NPSs were also considered as potential confounding factors based on the total severity score of the 12-item NPI-Q questionnaire, without the depression item. ${ }^{25,26}$ In addition, 4 NPS subsyndromes were defined according to the presence of different NPS domains: psychosis (delusions and/or hallucinations), apathy, affective disorders (depression and/or irritability and/or anxiety), and hyperactivity (disinhibition and/or euphoria, and/or agitation/aggression, and/or aberrant motor behavior). ${ }^{27}$ The presence of each subsyndrome was assessed using the first question of the NPI-Q questionnaire (ie, having or not one of the corresponding domains). The prescription of psychotropic drugs, classified according to the Anatomical Therapeutic Chemical classification, such as antipsychotics (N05A), anxiolytics (NO5B), hypnotics/sedatives (N05C), antidepressants (N06A), and 
Table 1

Characteristics of People With Dementia and Informal Caregiver in Each Country and in All Sample

\begin{tabular}{|c|c|c|c|c|c|c|c|c|c|c|c|c|c|c|c|}
\hline & \multirow{2}{*}{\multicolumn{2}{|c|}{$\frac{\text { Estonia }}{n=172(\%)}$}} & \multirow[t]{4}{*}{ * } & \multirow{2}{*}{\multicolumn{2}{|c|}{$\frac{\text { Finland }}{\mathrm{n}=182(\%)}$}} & \multirow[t]{4}{*}{ * } & \multirow{2}{*}{\multicolumn{2}{|c|}{$\frac{\text { France }}{\mathrm{n}=175(\%)}$}} & \multirow[t]{4}{*}{ * } & \multirow{2}{*}{\multicolumn{2}{|c|}{$\frac{\text { Germany }}{\mathrm{n}=116(\%)}$}} & \multirow[t]{4}{*}{$*$} & \multirow{2}{*}{\multicolumn{2}{|c|}{$\frac{\text { The Netherlands }}{\mathrm{n}=177(\%)}$}} & \multirow[t]{4}{*}{ * } \\
\hline & & & & & & & & & & & & & & & \\
\hline & \multirow{2}{*}{$\frac{\text { Depressed }}{90(52)}$} & \multirow{2}{*}{$\begin{array}{l}\text { Not } \\
\text { Depressed } \\
82(48)\end{array}$} & & \multirow{2}{*}{$\begin{array}{l}\text { Depressed } \\
55(30)\end{array}$} & \multirow{2}{*}{$\begin{array}{l}\text { Not } \\
\frac{\text { Depressed }}{127(70)}\end{array}$} & & \multirow{2}{*}{$\begin{array}{l}\text { Depressed } \\
53(30)\end{array}$} & \multirow{2}{*}{$\begin{array}{l}\text { Not } \\
\frac{\text { Depressed }}{122(70)}\end{array}$} & & \multirow{2}{*}{$\begin{array}{l}\text { Depressed } \\
58(50)\end{array}$} & \multirow{2}{*}{$\begin{array}{l}\text { Not } \\
\text { Depressed } \\
58(50)\end{array}$} & & \multirow{2}{*}{$\begin{array}{l}\text { Depressed } \\
4(25)\end{array}$} & \multirow{2}{*}{$\begin{array}{l}\text { Not } \\
\text { Depressed } \\
133(75)\end{array}$} & \\
\hline & & & & & & & & & & & & & & & \\
\hline \multicolumn{16}{|l|}{$\begin{array}{l}\text { Caregiver } \\
\text { demographic } \\
\text { characteristics }\end{array}$} \\
\hline Age (SD) & $54(12)$ & $58(12)$ & & $64(13)$ & $65(12)$ & .4 & $64(13)$ & $62(12)$ & .5 & $61(11)$ & $63(13)$ & .4 & $64(14)$ & $66(13)$ & .5 \\
\hline Sex female (\%) & $68(75)$ & $63(77)$ & .8 & $32(60)$ & $76(60)$ & .9 & $36(68)$ & $83(68)$ & .9 & $45(77)$ & $44(76)$ & .8 & $32(73)$ & $85(64)$ & .3 \\
\hline Zarith & $43(89)$ & $36(80)$ & & $31(54)$ & $27(126)$ & .06 & $39(52)$ & 28 (159) & & $34(58)$ & $29(58)$ & & $33(44)$ & $24(133)$ & \\
\hline GHQ-12 & $16(84)$ & $13(81)$ & & $12(55)$ & $11(125)$ & .2 & $15(52)$ & $11(122)$ & & $14(58)$ & $12(58)$ & .07 & $13(44)$ & $11(132)$ & .06 \\
\hline EQ-VAS & $63(90)$ & $69(82)$ & & $68(54)$ & $74(125)$ & & $66(53)$ & $75(121)$ & & $67(58)$ & $68(58)$ & .9 & $67(44)$ & $74(132)$ & \\
\hline $\begin{array}{l}\text { Hour of } \\
\text { supervision } \\
\text { per day }\end{array}$ & $1.9(90)$ & $1.9(82)$ & .8 & $1.3(53)$ & $1.2(121)$ & .3 & $1.8(49)$ & $1.3(118)$ & & $1.9(58)$ & $2(57)$ & .8 & $1.6(43)$ & $1.4(132)$ & .3 \\
\hline NPI-Q distress & $16(90)$ & $9.6(82)$ & & $14(55)$ & 7 (127) & & $22(51)$ & $8(122)$ & & $15(56)$ & $9(58)$ & & $17(44)$ & $9(133)$ & \\
\hline $\begin{array}{l}\text { Persons with } \\
\text { dementia's } \\
\text { characteristics }\end{array}$ & 172 & & & 182 & & & 175 & & & 116 & & & 177 & & \\
\hline Age (SD) & $82(7)$ & $81(8)$ & .1 & $81(5)$ & $83(6)$ & .09 & $82(8)$ & $84(5)$ & & $82(6)$ & $82(7)$ & 6 & $80(6)$ & $82(6)$ & .4 \\
\hline Sex female (\%) & $68(75)$ & $59(71)$ & .5 & $36(65)$ & $78(61)$ & .6 & $33(62)$ & $86(70)$ & .2 & $35(60)$ & $36(62)$ & .8 & $27(61)$ & $82(61)$ & .9 \\
\hline Charlson index & $2.5(902)$ & $2.5(82)$ & .7 & $2.2(55)$ & $1.7(127)$ & .4 & $2(53)$ & $1.5(122)$ & & $2.8(58)$ & $2.5(58)$ & .2 & $2(44)$ & $2.1(133)$ & .9 \\
\hline Cornell Scale & $16(51)$ & $6.6(82)$ & & $14(38)$ & $4.6(127)$ & & $17.4(35)$ & $4.2(122)$ & & $16(41)$ & $7(58)$ & & $15(37)$ & $5.3(133)$ & \\
\hline $\begin{array}{l}\% \text { of depression } \\
\text { in all sample }\end{array}$ & 8 & 14 & & 13.3 & 15.7 & & 10.6 & 16.4 & & 14.1 & 7.2 & & 21.7 & & \\
\hline NPI-Q severity & $11.6(90)$ & $7(82)$ & & $11(55)$ & $5.8(127)$ & & $14(53)$ & $5.5(122)$ & & $11(58)$ & $6.8(58)$ & & $13.7(44)$ & 10.1 & \\
\hline Katz & $2.5(88)$ & $3(82)$ & & $4(55)$ & $4(127)$ & .4 & $3(49)$ & 4 (117) & & $2(58)$ & $2.5(58)$ & .09 & $3(44)$ & $7.3(133)$ & \\
\hline MMSE & $9(82)$ & $11(82)$ & & $18(48)$ & $16(11)$ & .08 & $13(44)$ & $15(106)$ & .08 & $12(47)$ & $12(45)$ & .8 & $16(37)$ & $3(131)$ & .7 \\
\hline $\begin{array}{l}\text { Use of } \\
\text { psychotropic (\%) }\end{array}$ & $47(52)$ & $34(41)$ & .1 & $52(94)$ & $116(91)$ & .4 & $53(100)$ & $113(92)$ & & $41(71)$ & $43(74)$ & .6 & $28(63)$ & $14(123)$ & .3 \\
\hline
\end{tabular}

MMSE, Mini-Mental State Examination; SD, standard deviation.

${ }^{*} P$ value not reported if $P<.05$.

antidementia drugs (N06D) were considered as dichotomous variable (taking or not the psychotropic medication).

\section{Statistical Analyses}

Descriptive statistics were calculated and presented as mean \pm standard deviation, absolute number, and percentage, as appropriate, to report information of the whole sample and for each country. To describe the characteristics of the population, according to the presence of depression, Student's t-test and $\chi^{2}$ test were used. To test the association of depression, the independent variable, with burden, distress, and quality of life of the caregiver, 3 models of linear regression analysis were performed for each main outcome in the whole sample; in a first step the unadjusted model was performed, then the second model was adjusted by demographic characteristics (age and sex of both people with dementia and caregiver), and finally the third model was adjusted to all the potential confounders. After performing each regression, we undertook a test of multicollinearity between our independent variables using the variance inflation factor (VIF). To test the association between depression and our main outcome variations across the countries, we undertook a mixed-effect linear regression with a random effect of the level of the countries and with the interaction between the countries and the presence of depression. Results were adjusted for all confounders and presented as adjusted means obtained from the model.

Furthermore, a linear regression, using 4 different subsyndromes of NPSs (affective disorder, agitation, apathy, and psychotic symptoms) as dependent variables, was performed to evaluate the association between depression and our main outcomes despite the presence of other NPSs. Statistical significance was defined with a $P$ value of $<.05$. Analysis was carried out using STATA v 14.2 (StataCorp, College Station, TX).

\section{Results}

\section{Descriptive Statistics}

The descriptive characteristics of the entire sample and for each country are shown in Tables 1 and 2.

Among 1233 people with dementia living in the communitydwelling setting, 414 (34\%) people with dementia suffered from depression with an average CSDD score of 16 (standard deviation \pm 0.2 ). The degree of severity of the other NPSs, according to NPI-Q severity score, in people with dementia with depression was significantly higher than in people with dementia without depression.

The informal caregivers of depressed people with dementia displayed lower level of quality of life in terms of EQ-VAS scale than the informal caregiver of nondepressed people with dementia, although in one-half of the countries, this result was not statistically significant. Caregivers of depressed people with dementia showed higher level of burden defined by statistically significant higher Zarit score than the caregivers of nondepressed people with dementia, as well as a statistically significant higher level of distress, according to the distress score of the NPI-Q.

For the characteristics of people with dementia within countries, we observed that the averages of each characteristic displayed a similar trend of the entire sample except for the comorbidity level in Sweden, which was 1 point higher in the depressed participants compared with the nondepressed participants $(P<.05)$.

Both distress and burden of caregiver were negatively impacted by the presence of depression. In particular, in Spain, England, and 
Table 2

Characteristics of People With Dementia and Informal Caregiver in Each Country and in All Sample

\begin{tabular}{|c|c|c|c|c|c|c|c|c|c|c|c|c|}
\hline & \multicolumn{2}{|l|}{ Spain } & \multirow[t]{4}{*}{ * } & \multirow{2}{*}{\multicolumn{2}{|c|}{$\frac{\text { Sweden }}{\mathrm{n}=146(\%)}$}} & \multirow[t]{4}{*}{ * } & \multirow{2}{*}{\multicolumn{2}{|c|}{$\begin{array}{l}\text { England } \\
\mathrm{n}=81(\%)\end{array}$}} & \multirow[t]{4}{*}{ * } & \multirow{2}{*}{\multicolumn{2}{|c|}{$\frac{\text { All Sample }}{\mathrm{n}=1223(\%)}$}} & \multirow[t]{4}{*}{ * } \\
\hline & \multicolumn{2}{|c|}{$\mathrm{n}=174(\%)$} & & & & & & & & & & \\
\hline & Depressed & Not Depressed & & Depressed Not Depressed & Not Depressed & & \multirow{2}{*}{$\frac{\text { Depressed }}{30(37)}$} & \multirow{2}{*}{$\frac{\text { Not Depressed }}{51(63)}$} & & \multirow{2}{*}{$\frac{\text { Depressed }}{414(34)}$} & Not Depressed & \\
\hline & $51(29)$ & $123(71)$ & & $33(23)$ & $113(77)$ & & & & & & $809(66)$ & \\
\hline \multicolumn{13}{|l|}{$\begin{array}{l}\text { Caregiver's demographic } \\
\text { characteristics }\end{array}$} \\
\hline Age (SD) & $62(12)$ & $68(14)$ & & $72(12)$ & $71(12)$ & 6 & $62(12)$ & $67(12)$ & .09 & $62(13)$ & $65(13)$ & \\
\hline Sex female (\%) & $40(78)$ & $83(67)$ & .1 & $22(67)$ & $76(67)$ & 1 & $20(66)$ & $34(67)$ & 1 & $269(67)$ & $506(62)$ & .4 \\
\hline Zarith & $41(51)$ & $32(123)$ & & $42(33)$ & $28(113)$ & & $44(30)$ & $32(51)$ & & $38(411)$ & $29(805)$ & \\
\hline GHQ-12 & $17(51)$ & $14(122)$ & & $16(33)$ & $11(113)$ & & $16(30)$ & $11(51)$ & & $15(412)$ & $12(805)$ & \\
\hline EQ-VAS & $59(51)$ & $61(123)$ & .6 & $63(33)$ & $69(113)$ & .4 & $69(30)$ & $71(51)$ & .7 & $65(413)$ & $70(805)$ & \\
\hline Hour of supervision per day & $2.5(51)$ & $1.8(120)$ & & $1.6(33)$ & $1.4(112)$ & .3 & $1.9(29)$ & $1.4(50)$ & .07 & $1.8(406)$ & $1.5(792)$ & \\
\hline NPI-Q distress & $14(51)$ & $6.5(122)$ & & $18(29)$ & $9(51)$ & & $16(409)$ & $8.3(807)$ & & 17 (409) & $8(807)$ & \\
\hline $\begin{array}{l}\text { Persons with dementia's } \\
\text { characteristics }\end{array}$ & 174 & & & 146 & & & 81 & & & 1223 & & \\
\hline Age (SD) & $84(7)$ & $82(7)$ & .06 & $82(6)$ & $82(6)$ & .8 & $80(8)$ & $81(6)$ & .8 & $82(7)$ & $82(6)$ & .7 \\
\hline Sex female (\%) & $35(68)$ & $80(65)$ & .6 & $16(48)$ & $55(48)$ & .9 & $19(63)$ & $30(58)$ & .6 & $269(65)$ & $506(62)$ & .4 \\
\hline Charlson index & $2.5(51)$ & $1.6(123)$ & & $3.4(33)$ & $2.5(113)$ & & $1.9(30)$ & $1.9(51)$ & .8 & $2.4(414)$ & $1.9(809)$ & \\
\hline Cornell Scale & $18.2(35)$ & $5(123)$ & & $17(28)$ & $5(113)$ & & $16(19)$ & $6(51)$ & & $16(284)$ & $5.2(809)$ & \\
\hline$\%$ of depression in all sample & 12.8 & 15.1 & & 12.3 & 15.2 & & 7.2 & 6.3 & & 100 & 100 & \\
\hline NPI-Q severity & $11.1(51)$ & $5.3(123)$ & & $11.6(33)$ & $7.6(113)$ & & $14(30)$ & $8.7(51)$ & & $12(414)$ & $6.6(809)$ & \\
\hline Katz & $2(51)$ & $3.5(123)$ & & $3(33)$ & $3.5(113)$ & .2 & $3(30)$ & $4(50)$ & .1 & $3(408)$ & $3.5(801)$ & \\
\hline MMSE & $14(31)$ & $17(105)$ & & $16(25)$ & $15(103)$ & .7 & $13(18)$ & $14(42)$ & .5 & $13(332)$ & 15 (717) & \\
\hline Use of psychotropic (\%) & $46(90)$ & $116(94)$ & & $24(72)$ & $92(81)$ & .3 & $19(63)$ & $35(68)$ & .6 & $310(75)$ & $621(76)$ & .4 \\
\hline
\end{tabular}

MMSE, Mini-Mental State Examination; SD, standard deviation.

${ }^{*} P$ value not reported if $P<.05$.

Sweden, there was at least a difference of 5 points more for caregivers caring for depressed people with dementia compared with nondepressed people with dementia according to the Zarit scale.

\section{Regression Results}

Tables 3 and 4 display the association between depression and the main outcomes evaluated for the entire sample.

VIF values suggest the absence of multicollinearity between the independent variables in the models (VIF values $=1.23$ ).

\section{Depression in People With Dementia and Informal Caregiver Burden} and Distress

An association was found between depression and caregiver burden, both in terms of the Zarit scale and hours of supervision after controlling for all confounders. Moreover, a significant association was also found between informal caregiver distress and depression, according to NPI-Q distress score (Zarit: $\beta 3.7 ; P=.001$; hour of supervision: $\beta 1.7 ; P=.004$; NPI distress: $\beta 1.2 ; P=.002$ ).

Spain, Sweden, and England exhibited the highest score in Zarit scale, whereas France, Finland, and Germany displayed almost the same burden for both populations. Estonia and England were the countries with the highest number of hours employed in the supervision of depressed people with dementia. Finally, in all countries, the caregiver of depressed people with dementia displayed greater distress compared with the caregivers of nondepressed people with dementia in terms of NPI-Q distress score.

\section{Depression in People With Dementia and Informal Caregiver Quality of Life}

Concerning quality of life, a significant association was found between depression and psychological well-being of the informal caregiver, in terms of GHQ-12 score, and with the overall vision of quality of life, according to the VAS score (GHQ-12: $\beta 1.8 ; P<.001$; EQ-VAS: $\beta-4.1 ; P=.003$ ) (Table 3 ).

In all the countries, especially in Estonia and France, the presence of depression was associated with a reduction of the overall and psychological quality of life, excluding Germany, which shows the same scores for both scales of assessment in the 2 populations.

After testing the random effect of each country on the different outcomes and having demonstrated the existence of a significant change, we report in the adjusted averages of the main outcomes for each country (Supplementary Table 1).

\section{Association Between Depression and Main Outcomes Adjusted by Other Cluster of NPS}

The results of this analysis display how, even while coexisting depression with other clusters of NPS, depression remains independently associated with a decreased quality of life and with an increased burden and distress of informal caregiver. The results are reported in Table 5 .

Table 3

Association Between Depression in People With Dementia and Burden and Distress of Informal Caregiver in All Sample Size

\begin{tabular}{|c|c|c|c|c|c|c|c|c|c|}
\hline \multirow[t]{2}{*}{ Outcomes } & \multicolumn{3}{|c|}{ Unadjusted } & \multicolumn{3}{|c|}{ Demographic } & \multicolumn{3}{|c|}{ All Confounders* } \\
\hline & $\beta$ & $P$ Value & Confidence interval & $\beta$ & $P$ Value & Confidence interval & $\beta$ & $P$ Value & Confidence interval \\
\hline Zarit & 9.1 & $<.001$ & $(7.3 ; 10.9)$ & 8.8 & $<.001$ & $(7 ; 10.6)$ & 3.7 & .001 & $(1.55 ; 5.8)$ \\
\hline Hours of supervision per day & 2.8 & $<.001$ & $(1.9 ; 3.9)$ & 3.4 & $<.001$ & $(2.4 ; 4.3)$ & 1.7 & .004 & $(0.5 ; 2.9)$ \\
\hline NPI-Q distress & 8.2 & $<.001$ & $(7.2 ; 9.2)$ & 8.2 & $<.001$ & $(7.1 ; 9.2)$ & 1.2 & .002 & $(0.4 ; 1.9)$ \\
\hline
\end{tabular}

\footnotetext{
*Adjusted by demographic characteristics (sex and age of both people with dementia and caregiver).
} 
Table 4

Association Between Depression in People With Dementia and Quality of Life of Informal Caregiver in All Sample Size

\begin{tabular}{|c|c|c|c|c|c|c|c|c|c|}
\hline \multirow[t]{2}{*}{ Outcomes } & \multicolumn{3}{|c|}{ Unadjusted } & \multicolumn{3}{|c|}{ Demographic } & \multicolumn{3}{|c|}{ All Confounders* } \\
\hline & $\beta$ & $P$ Value & Confidence interval & $\beta$ & $P$ Value & Confidence interval & $\beta$ & $P$ Value & Confidence interval \\
\hline GHQ-12 & 3.1 & $<.001$ & $(2.4 ; 3.7)$ & 3 & $<.001$ & $(2.3 ; 3.7)$ & 1.8 & $<.001$ & $(1.04 ; 2.7)$ \\
\hline EQ-VAS & -4.9 & $<.001$ & $(-7.1 ;-2.7)$ & -5.6 & $<.001$ & $(-7.8 ;-3.5)$ & -4.1 & .003 & $(-6.9 ;-; 1.4)$ \\
\hline
\end{tabular}

*Adjusted by demographic characteristics (sex and age of both people with dementia and caregiver).

\section{Discussion}

The results of this study have shown that depression in people with dementia was independently associated with an increased burden and distress of informal caregivers and a reduction of their quality of life. This association remains significant despite the presence of other clusters of NPSs.

The results of this study are in line with previous findings showing that the presence of NPSs in people with dementia is associated with both increased burden and lower quality of life of caregivers, ${ }^{16,28-30}$ thus extending the current knowledge with a focus on depression and offering a detailed overview in 8 European countries.

Furthermore, to our knowledge, this is the first study, based on data from 8 European countries, analyzing the impact of depression in people with dementia on the informal caregiver burden, in terms of hours of supervision.

Although the association between depression and burden and quality of life of informal caregivers is clear in most countries, some countries, such as Germany and Finland, do not follow the same trend. For instance, in Spain there are strong cultural values that promote taking care of older patients within the family systems, and institutionalization is the last resource when the family cannot provide the required care. Moreover, the number of hours that the family caregiver provides to the people with dementia is very high; in many cases, it is a full-time commitment. These cultural values coexist with an institutional long-term care system that cannot be afforded by many cases and a social community support that needs to be improved for people with dementia and their caregivers. ${ }^{31}$ This discrepancy might be explained by the fact that intrinsic characteristics of informal caregiver, such as self-efficacy and environmental determinants, as well as socio-cultural factors and healthcare policy, may influence the level of burden that they perceive. ${ }^{16,18,32}$

Concerning the associations between depression and caregiver burden and well-being, compared with the other NPS clusters, the literature findings are conflicting. ${ }^{33}$ Psychotic and disruptive behaviors were the mostly cited clusters of NPSs having a negative impact on caregiver burden, ${ }^{34}$ but for quality of life, negative syndromes such as apathy and depression, seem to play a more important role. ${ }^{32}$

Moreover, although "positive" syndromes, such as agitation and irritability, were frequently considered as the major cause of burden and distress, ${ }^{32}$ it is important to remember that often these "syndromes" are actually featured symptoms of clinical depression. ${ }^{35}$ Our results show how depression remains significantly associated with both of our main outcomes, despite the presence of other NPS.

Serotonin reuptake inhibitor antidepressants are often considered as first-line pharmacologic agents to treat depression in people with dementia. Recent results from the clinical trial Citalopram for agitation in Alzheimer disease (CitAD) reported a significant effect of citalopram for treating several NPS such as agitation, delusions, anxiety, and irritability/lability in patients with Alzheimer's disease (AD). ${ }^{36,37}$ However, it is known that the pharmacologic strategies adopted to treat depression in people with dementia are not often enough to guarantee a successful management of these patients, in the community-dwelling setting. ${ }^{14,38,39}$ Furthermore, caregivers' psychological well-being was associated with, among other things, less caregiver burden and higher quality of life.

Our study is based on a large sample size of which $55 \%$ is affected by $\mathrm{AD}$ and depression. The main independent variable of this analysis was assessed using the Cornell scale, which is precisely designed and validated for the diagnosis of depression in people with dementia. ${ }^{21}$ As a consequence, the depression prevalence of $34 \%$ found in our study could be considered as more accurate than those shown in previous reports that are conflicting, with a variation of the estimated prevalence from $4 \%$ to $40 \%{ }^{12,13}$ Indeed, comparison of depression prevalence in patients with $\mathrm{AD}$ is difficult, as the clinical definitions used, the symptoms severity and the populations studied differ between studies. In addition, Chi et al highlighted in a large meta-analysis the importance of a standardized diagnostic approach for the evaluation of depression prevalence in patients with AD. Their results showed a $14 \%$ rate of major depression according to Diagnostic and Statistical Manual of Mental Disorder criteria vs 40\% using the specific criteria for dementia in patients with mild AD. ${ }^{40}$ Another strength of our study is that the main outcomes were based on 2 different validated scales for assessing quality of life and 2 different features of the burden (Zarit scale and hours of supervision in terms of Resource Utilization in Dementia questionnaire).

The main limitations of this study consist in the cross-sectional design that prevent us from investigating the association between depression in people with dementia and the main outcomes over time; furthermore, this is a secondary data analysis, therefore examining the association between depression in people with dementia

Table 5

Regression Analysis Between Depression and Other Cluster of NPS According to our Main Outcomes

\begin{tabular}{|c|c|c|c|c|c|c|c|c|c|c|c|c|c|c|c|}
\hline & \multicolumn{3}{|c|}{ Zarit Score } & \multicolumn{3}{|c|}{ Hour of Supervision } & \multicolumn{3}{|c|}{ NPI Distress } & \multicolumn{3}{|c|}{ GHQ-12 Score } & \multicolumn{3}{|c|}{ VAS Score } \\
\hline & $\beta$ & $P$ Value & Charlson Index & $\beta$ & $P$ Value & Charlson Index & $\beta$ & $P$ Value & Charlson Index & $\beta$ & $P$ Value & Charlson Index & $\beta$ & $P$ Value & Charlson Index \\
\hline Agitation & 4.1 & .002 & $(1.9 ; 6.1)$ & 1.6 & .005 & $(0.5 ; 2.8)$ & 1.1 & .004 & $(0.3 ; 1.8)$ & 1.9 & $<.001$ & $(1.1 ; 2.7)$ & -4.1 & .004 & $(-6.8 ;-1.2)$ \\
\hline Psychotic & 3.4 & .002 & $(1.2 ; 5.5)$ & 1.6 & .005 & $(0.49 ; 2.8)$ & 1.2 & .001 & $(0.49 ; 1.9)$ & 1.8 & $<.001$ & $(0.9 ; 2.6)$ & -3.7 & .008 & $(-6.5 ;-0.9)$ \\
\hline Apathy & 3.7 & .001 & $(1.6 ; 5.8)$ & 1.6 & .005 & $(0.55 ; 2.9)$ & 1.2 & .001 & $(0.48 ; 1.9)$ & 1.8 & $<.001$ & $(1.1 ; 2.6)$ & -4.1 & .003 & $(-6.8 ;-1.4)$ \\
\hline $\begin{array}{l}\text { Affective } \\
\text { disorders }\end{array}$ & 3.6 & .001 & $(1.5 ; 5.8)$ & 1.7 & .004 & $(0.5 ; 2.9)$ & 1.2 & .002 & $(0.45 ; 1.9)$ & 1.8 & $<.001$ & $(1.04 ; 2.6)$ & -4.1 & .003 & $(-6.9 ;-1.4)$ \\
\hline
\end{tabular}

NPI, Neuropsychiatric Questionnaire without depression item. 
and the onset or worsening of depression in the informal caregiver was not possible.

Often, NPSs and especially depression have been shown to have a greater negative impact in the caregiver's life than cognitive disorders, such as memory complaint. ${ }^{41}$

Given the impact of depression among people with dementia on burden, distress, and quality of life of informal caregivers, it is crucial to detect depression in people with dementia over the course of the disease, a condition often underdiagnosed in this population. ${ }^{12} \mathrm{~A}$ correct diagnostic timing could help the clinician find specific coping strategies and other nonpharmacologic treatments to manage people with dementia at home, reduce the informal caregiver's burden, and preserve their quality of life. ${ }^{36,42-44}$

Supporting informal caregivers in the home management of people with dementia is a challenge to reduce the onset of adverse events, such as mortality, and health costs related to institutionalization. ${ }^{45}$

\section{Conclusions and Implications}

The results of this study show that depression in people with dementia is associated with an increased burden and distress of informal caregivers and a reduction of their quality of life. This association remains significant despite the presence of other NPSs. Further studies are needed to assess if providing tailored strategies for optimizing diagnosis and managing of depression in people with dementia might be a strategy of choice to improve caregiver quality of life and to reduce their burden in the community-dwelling setting.

\section{References}

1. World Alzheimer Report 2018. The State of the Art of Dementia Research: New frontiers. New Front 48 C.Patterson - Alzheimer's Disease International (ADI): London, UK, 2018

2. Feast A, Moniz-Cook E, Stoner C, et al. A systematic review of the relationship between Behavioral and Psychological Symptoms (BPSD) and caregiver wellbeing. Int Psychogeriatr 2016;28:1761-1774.

3. Majer R, Simon V, Csiba L, et al. Behavioural and psychological symptoms in neurocognitive disorders: Specific patterns in dementia subtypes. Open Med 2019;14:307-316.

4. Kwok Y-T, Chen C-Y, Chiu M-J, et al. Assessment of behavioral and psychological symptoms of dementia by family caregivers. Arch Gerontol Geriatr 2011;52:60-65.

5. Arthur PB, Gitlin LN, Kairalla JA, Mann WC. Relationship between the number of behavioral symptoms in dementia and caregiver distress: What is the tipping point? Int Psychogeriatr 2018;30:1099-1107.

6. Crellin N, Charlesworth G, Orrell M. Measuring family caregiver efficacy for managing behavioral and psychological symptoms in dementia: A psychometric evaluation. Int Psychogeriatr 2014;26:93-103.

7. Balieiro AP Jr, Sobreira EST, Pena MCS, et al. Caregiver distress associated with behavioral and psychological symptoms in mild Alzheimer's disease. Dement Neuropsychol 2010;4:238-244.

8. Kamiya M, Sakurai T, Ogama N, et al. Factors associated with increased caregivers' burden in several cognitive stages of Alzheimer's disease: Caregivers' burden in Alzheimer's disease. Geriatr Gerontol Int 2014:14:45-55.

9. Mukherjee A, Biswas A, Roy A, et al. Behavioural and psychological symptoms of dementia: Correlates and impact on caregiver distress. Dement Geriatr Cogn Disord Extra 2017;7:354-365.

10. Fauth EB, Zarit SH, Femia EE, et al. Behavioral and psychological symptoms of dementia and caregivers' stress appraisals: Intra-individual stability and change over short-term observations. Aging Ment Health 2006;10:563-573.

11. Koyama A, Matsushita M, Hashimoto M, et al. Mental health among younger and older caregivers of dementia patients: Mental health of dementia caregivers. Psychogeriatrics 2017;17:108-114.

12. Puranen $\mathrm{A}$, Taipale $\mathrm{H}$, Koponen $\mathrm{M}$, et al. Incidence of antidepressant use in community-dwelling persons with and without Alzheimer's disease: 13-year follow-up. Int J Geriatr Psychiatry 2017;32:94-101.

13. Zhao Q-F, Tan L, Wang H-F, et al. The prevalence of neuropsychiatric symptoms in Alzheimer's disease: Systematic review and meta-analysis. J Affect Disord 2016;190:264-271.

14. Ford AH, Almeida OP. Management of depression in patients with dementia: Is pharmacological treatment justified? Drugs Aging 2017:34:89-95.

15. Perna L, Wahl HW, Weberpals J, et al. Incident depression and mortality among people with different types of dementia: Results from a longitudinal cohort study. Soc Psychiatry Psychiatr Epidemiol 2019;54:793-801.
16. Hurt C, Bhattacharyya S, Burns A, et al. Patient and caregiver perspectives of quality of life in dementia. Dement Geriatr Cogn Disord 2008;26:138-146.

17. Verbeek H, Meyer G, Leino-Kilpi H, et al. A European study investigating patterns of transition from home care towards institutional dementia care: The protocol of a Right Time Place Care study. BMC Public Health 2012;12: 68

18. Molloy DW, Alemayehu E, Roberts R. Reliability of a standardized mini-mental state examination compared with the traditional Mini-Mental State Examination. Am J Psychiatry 1991;148:102-105.

19. Zarit SH, Reever KE, Bach-Peterson J. Relatives of the impaired elderly: Correlates of feelings of burden. The Gerontologist 1980;20:649-655.

20. RUD - Resource Utilization in Dementia. Available at: https://eprovide.mapitrust.org/instruments/resource-utilization-in-dementia. Accessed October 29, 2019.

21. Alexopoulos GS, Abrams RC, Young RC, Shamoian CA. Cornell scale for depression in dementia. Biol Psychiatry 1988;23:271-284.

22. Katz S, Ford AB, Moskowitz RW, et al. Studies of illness in the aged. The index of ADL: A standardized measure of biological and psychosocial function. JAMA 1963;185:914-919.

23. Charlson ME, Pompei P, Ales KL, MacKenzie CR. A new method of classifying prognostic comorbidity in longitudinal studies: Development and validation. J Chronic Dis 1987;40:373-383.

24. Folstein MF, Folstein SE, McHugh PR. "Mini-mental state". A practical method for grading the cognitive state of patients for the clinician. J Psychiatr Res 1975; 12:189-198.

25. Cummings JL, Mega M, Gray K, et al. The Neuropsychiatric Inventory: Comprehensive assessment of psychopathology in dementia. Neurology 1994; 44:2308-2314.

26. Kaufer DI, Cummings JL, Ketchel P, et al. Validation of the NPI-Q a brief clinical form of the neuropsychiatric inventory. J Neuropsychiatry Clin Neurosci 2000; 12:233-239.

27. Canevelli M, Adali N, Voisin T, et al. Behavioral and psychological subsyndromes in Alzheimer's disease using the Neuropsychiatric Inventory. Int J Geriatr Psychiatry 2013;28:795-803.

28. Torrisi M, De Cola MC, Marra A, et al. Neuropsychiatric symptoms in dementia may predict caregiver burden: A Sicilian exploratory study: BPSD and caregiver burden. Psychogeriatrics 2017:17:103-107.

29. Cova I, Travi N, Maggiore L, et al. What are the caregivers' needs on dementia care? An integrated qualitative and quantitative assessment. Neurol Sci 2018; 39:1085-1091.

30. Bremer P, Cabrera E, Leino-Kilpi H, et al. Informal dementia care: Consequences for caregivers' health and health care use in 8 European countries. Health Policy 2015;119:1459-1471.

31. Afram B, Stephan A, Verbeek H, et al. Reasons for institutionalization of people with dementia: Informal caregiver reports from 8 European countries. J Am Med Dir Assoc 2014;15:108-116.

32. Feast A, Orrell M, Russell I, et al. The contribution of caregiver psychosocial factors to distress associated with behavioural and psychological symptoms in dementia: Psychosocial model of BPSD-related distress. Int J Geriatr Psychiatry 2017:32:76-85.

33. Ornstein KA, Gaugler JE, Devanand DP, et al. Are there sensitive time periods for dementia caregivers? The occurrence of behavioral and psychological symptoms in the early stages of dementia. Int Psychogeriatr 2013;25: $1453-1462$.

34. Baharudin AD, Din NC, Subramaniam P, Razali R. The associations between Behavioral-psychological Symptoms of Dementia (BPSD) and coping strategy, burden of care and personality style among low-income caregivers of patients with dementia. BMC Public Health 2019;19:447.

35. Fauth EB, Gibbons A. Which behavioral and psychological symptoms of dementia are the most problematic? Variability by prevalence, intensity, distress ratings, and associations with caregiver depressive symptoms: Variability in BPSD identified as most problematic. Int J Geriatr Psychiatry 2014;29: $263-271$.

36. Hughes LD, Murphy F, Findlay DJ. Assessment and treatment of depression associated with dementia. Br J Hosp Med 2019;80:151-156.

37. Leonpacher AK, Peters ME, Drye LT, et al. Effects of citalopram on neuropsychiatric symptoms in Alzheimer's dementia: Evidence from the CitAD Study. Am J Psychiatry 2016;173:473-480.

38. Kok RM, Reynolds CF. Management of depression in older adults: A review. JAMA 2017:317:2114.

39. Nelson JC, Devanand DP. A systematic review and meta-analysis of placebocontrolled antidepressant studies in people with depression and dementia. J Am Geriatr Soc 2011;59:577-585.

40. Chi S, Wang C, Jiang T, et al. The prevalence of depression in Alzheimer's disease: A systematic review and meta-analysis. Curr Alzheimer Res 2015;12: 189-198.

41. Zauszniewski JA, Lekhak N, Musil CM. Caregiver reactions to dementia symptoms: Effects on coping repertoire and mental health. Issues Ment Health Nurs 2018;39:382-387.

42. Hsu T-J, Tsai H-T, Hwang A-C, et al. Predictors of nonpharmacological intervention effect on cognitive function and behavioral and psychological symptoms of older people with dementia: Nonpharmacological intervention for dementia. Geriatr Gerontol Int 2017;17:28-35. 
43. Terayama H, Sakurai H, Namioka N, et al. Caregivers' education decreases depression symptoms and burden in caregivers of patients with dementia: Caregiver depression and burden. Psychogeriatrics 2018;18: 327-333.

44. Kales HC, Gitlin LN, Stanislawski B, et al. WeCareAdvisor ${ }^{\mathrm{TM}}$ : The development of a caregiver-focused, web-based program to assess and manage behavioral and psychological symptoms of dementia. Alzheimer Dis Assoc Disord 2017; 31:263-270.

45. Alvira MC, Risco E, Cabrera E, et al. The association between positive-negative reactions of informal caregivers of people with dementia and health outcomes in eight European countries: A cross-sectional study. J Adv Nurs 2015;71: 1417-1434. 


\section{Supplementary Material}

The Right Time Place Care Consortium partners are as follow: Coordinator: University of Witten/Herdecke (DE): Gabriele Meyer $\mathrm{PhD}, \mathrm{RN}$ professor (scientific coordinator, WP1 leader), Astrid Stephan, MScN, RN, Anna Renom Guiteras, geriatrician, Dirl Sauerland Dr. re, pol., professor (WP 4 \& 6 leader), Dr Ansgar Wubker, Patrick Bremer. Consortium Member: Maastricht University (NL): Jan P.H. Hamers $\mathrm{PhD}, \mathrm{RN}$, professor (WP3 leader); Basema Afram MSc, Hanneke C. Beerens MSc, RN, Michel H.C. Bleijlevens, PhD, PT; Hilde Veerbek, PhD; Sandra M. G. Zwakhalen, PhD, RN; Dirk Ruwaard, MD, professor. Lund University (SE): Ingalill Rahm Hallberg, professor (WP2 leader); Ulla Melin Emilsson, professor; Staffan Karlsson PhD. University of Manchester (UK): David Challis professor, Caroline Sutcliffe; Dr David
Jolley; Sue Tucker; Ian Browns; Brenda Roe, professor; Alistair Burns, professor. University of Turku (FI): Helena Leino-Kilpi, PhD RN, professor; Jaana Koskenniemi, MNSc, RN, researcher; Riitta Suhonen, PhD, RN, professor; Matti Viitanen, MD, PhD, professor; Seija Arve, PhD, RN, adj professor; Minna Stolt, MNSc; Maija Hupli, PhD, RN. University of Tartu (EE): Kai Saks, MD, PhD, professor (WP 5 leader); Ene-Margit Tiit, PhD, professor; Jelena Leibur, MD, MBA; Katrin Raamat, MA; Angelika Armolik, MA; Teija Tuula Marjatta Toivari, RN; Fundació Privada Clinic per la Recerca Biomedica, Hospital Clinic of Barcelona (ES): Adelaida Zabalegui, PhD, RN (WP 5 leader); Montserrat Navarro, $\mathrm{PhD}, \mathrm{RN}$; Esther Cabrera PhD, RN (Tecnocampus Mataró), Ester Risco, MNSc, RN. Gerontôpole, University of Toulouse (FR): Dr Maria Soto; Agathe Milhet; Dr Sandrine Sourdet; Sophie Gillette; Bruno Vellas, professor.

Supplementary Table 1

Association Between Depression in Burden, Distress, and Quality of Life of Informal Caregiver Within Countries (Adjusted Averages)

\begin{tabular}{|c|c|c|c|c|c|c|c|c|}
\hline & \multicolumn{2}{|l|}{ Estonia } & \multicolumn{2}{|l|}{ Finland } & \multicolumn{2}{|l|}{ France } & \multicolumn{2}{|l|}{ Germany } \\
\hline & Depressed & Not Depressed & Depressed & Not Depressed & Depressed & Not Depressed & Depressed & Not Depressed \\
\hline Zarit & 38 & 35 & 31 & 31 & 33 & 34 & 28 & 29 \\
\hline Hours of supervision per day & 11 & 8 & 7 & 7 & 6 & 6 & 3 & 1 \\
\hline NPI-Q distress & 12 & 11 & 11 & 10 & 14 & 11 & 12 & 11 \\
\hline GHQ-12 & 16 & 13 & 12 & 11 & 14 & 12 & 12 & 12 \\
\hline \multirow[t]{3}{*}{ EQ-VAS } & 61 & 68 & 68 & 73 & 70 & 72 & 69 & 69 \\
\hline & \multicolumn{2}{|c|}{ The Netherlands } & \multicolumn{2}{|l|}{ Spain } & \multicolumn{2}{|l|}{ Sweden } & \multicolumn{2}{|l|}{ England } \\
\hline & Depressed & Not Depressed & Depressed & Not Depressed & Depressed & Not Depressed & Depressed & Not Depressed \\
\hline Zarit & 28 & 24 & 40 & 35 & 42 & 29 & 41 & 33 \\
\hline Hours of supervision per day & 5 & 4 & 8 & 8 & 3 & 3 & 12 & 7 \\
\hline NPI-Q distress & 11 & 10 & 12 & 10 & 13 & 11 & 10 & 9 \\
\hline GHQ-12 & 12 & 12 & 16 & 15 & 16 & 12 & 15 & 12 \\
\hline EQ-VAS & 71 & 74 & 60 & 61 & 69 & 71 & 69 & 71 \\
\hline
\end{tabular}

